\title{
Comparative study of new MPPT control approaches for a photovoltaic system
}

\author{
Ahmed Haddou, Nour-EddineTariba, Naima ikken, Abdelhadi Bouknadel, Hafsa EL Omari, \\ Hamid EL Omari \\ Department of the Physics and Engineering Science, Laboratory ERED, Hassan I University, Morocco
}

\begin{tabular}{l} 
Article Info \\
\hline Article history: \\
Received Jun 2, 2019 \\
Revised Jul 9, 2019 \\
Accepted Aug 2, 2019 \\
\hline Keywords: \\
Boost Converter \\
Incremental Conductance \\
MPPT \\
MRAC \\
Sliding mode controller
\end{tabular}

Sliding mode controller

\begin{abstract}
The output characteristics of the photovoltaic (PV) installation normally depend on solar radiation and ambient temperature, the charge impedance, its maximum power point (MPP) is not steady. In every state of the PV module has a point where it can create its MPP. Thus, MPPT (maximum point power monitoring) process can be employed to keep the photovoltaic panel running on its MPP. In this article, the objective was to determine how the different maximum point power monitoring (MPPT) techniques applied to PV systems work. Therefore, two MPPT algorithms are offered and compared under several situation of temperature and radiation conditions: MRAC methods and sliding mode controller combined with the Incremental Conductivity (IC) algorithm. They are often employed due to their low price and simple use. They have been tested on their performance employing the PSIM software with different situations of temperature and solar radiation
\end{abstract}

This is an open access article under the CC BY-SAlicense.

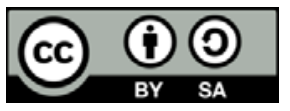

\section{Corresponding Author:}

Ahmed Haddou,

Department of the Physics and Engineering Science,

Hassan I University, FSTS, Km7, Road Casablanca, Settat, Morocco.

Email: haddou@gmail.com

\section{INTRODUCTION}

Nowadays, much of the world's energy production is provided by fossil fuels, the consumption of these sources rises the greenhouse effect and thus, increase pollution. Solar renewable energy is an important solution that contributes to minimize pollution. The production of this energy is not linear because the operating point of the photovoltaic panel (PV) does not always coincide with the point of maximum power. To have the best performance of the photovoltaic panel at all times, we use a maximum point researching and tracking mechanism called MPPT $[1,2]$.

As a consequence, numerous studies have concentrated on photovoltaic systems. They attempted to create algorithms to have the best energy performance from the PV and have better yield [2, 3]. Hill Climbing, $\mathrm{P} \& \mathrm{O}$, and Conductance Increment (INC) [3] was precursor in this domain. There are also others advanced methods based on fuzzy logic (FL) $[4,5]$.

In this article, the objective was to study the operation of various MPPT techniques applied to PV systems. Therefore, two MPPT algorithms are presented and compared under various temperature and radiation conditions: MRAC methods and incremental conductance based sliding mode controller. These algorithms are widely used in PV systems because of their easy implementation and low cost. These techniques were analyzed and their performance evaluated using the PSIM software under different types of solar radiation and temperature. 


\section{PHOTOVOLTAICSYSTEM}

Fixed charge systems that use renewable energy as a source of energy always need an intermediate stage between the photovoltaic source and the load to get the most power available at any moment $[6,7]$, the intermediate stage used is a converter DC-DC as shown below:

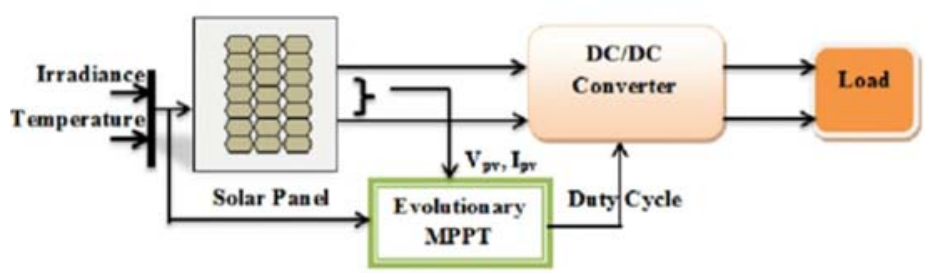

Figure 1. Diagram of PV connected to a load

\subsection{Photovoltaic panel}

The photovoltaic panel consists of cells in series and in parallel that transform the sunlight into an electric current, the equivalent model of a cell is a current source in parallel with a diode in parallel and an internal resistance that reflects the internal heating of each cell, the variation of the output voltage with the current of a cell is defined by a resistor in series with the current source.Figure 2.

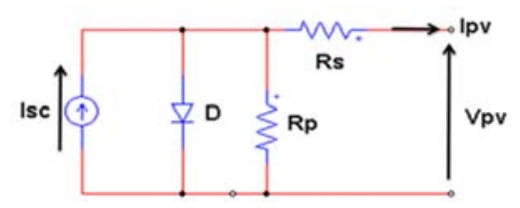

Figure 2. Electrical model of PV module

The output current-voltage (I-V) characteristics can be calculated by using the following equation [4]

$$
i_{p v}=N_{p} i_{S C}-N_{p}\left(e^{\frac{V_{P V}}{N_{S} V_{T \alpha}}+\frac{R_{S} i_{P V}}{N_{S} V_{T} \alpha}}-1\right)-\frac{v_{p v}}{R_{p}}-\frac{R_{S}}{R_{P}} i_{p v}
$$

$\mathrm{i}_{\text {sc }}$ : short-circuit current of PV cell, $\mathrm{R}_{\mathrm{p}}$ : Shunt Resistor, Rs: resistor series, $\mathrm{i} 0$ is the reverse saturation current of the diode. VT is the thermal voltage; it depends exclusively on the temperature. Ns number of serie cell, $\mathrm{Np}$ number of parallel cells.

In this study, the SCHOTT POLY 240 module [7] is taken into account, the electrical characteristics of the module are shown in the Table 1:

Table 1. Electrical characteristics of PV module

\begin{tabular}{cc}
\hline Pmpp (Nominal Power) [Wp] & $\geq 240$ \\
\hline Vmpp (Voltage at Nominal Power) [V] & 30.4 \\
Impp (Current at Nominal Power) [A] & 7.90 \\
Voc (Open-Circuit Voltage) [V] & 37.3 \\
Isc (Short-Circuit Current) [A] & 8.47 \\
\hline
\end{tabular}

Figure 3 shows the variation of GPV current as a function of GPV voltage, while Figure 4 shows the variation of the GPV power provided by the voltage function under normal conditions $[4,5]$.

The characteristics $I_{p v} V s V_{p v}$ of the panel is a non-linear function, its linearization is required to study the dynamic behavior of systems (PV + boost) which strongly depends on the operating point of the photovoltaic generator, the linear model of MPP is given in Figure 3.

Int J Pow Elec \& Dri Syst Vol. 11, No. 1, Mar 2020 : $251-262$ 
The model in Figure 3 has validity at the linearization point, which is a suitable approximation for the small signals analysis. While it is desirable to operate at the maximum point at all times, the GPV panel may change the area of the operating point of the source voltage or the current area $[6,7]$.

The dynamic behaviour of the entire system, solar panel and power plant, depends strongly on the panel's operating point. For the purpose of designing the control system and ensuring the stability under all operating conditions, the photovoltaic module is also linearized at both current and voltage zones by using (3) and (4). The derivative of the non-linear function $I_{p v} v s V_{p v}$ at the MPP operating point is given below:

$$
\left.\frac{d i_{p v}}{d v_{p v}}\right|_{\substack{i_{p v}=I_{m p} \\ v_{p v}=V_{m p}}}=g\left(I_{m p}, V_{m p}\right)=-\frac{N_{P} I_{0}}{N_{S} V_{T} a}\left(e^{\frac{V_{m p}+R_{S} I_{m p}}{N_{S} V_{T} a}}-1\right)-\frac{1}{R_{p}}
$$

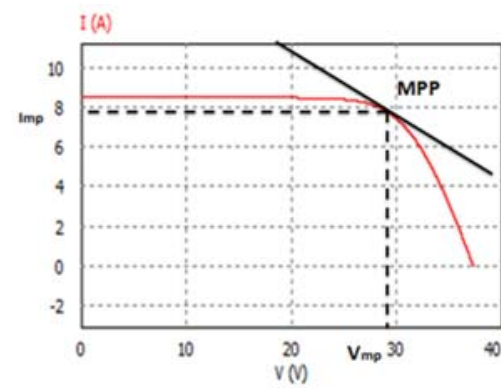

Figure 3. Current Ipv. voltage Vpv characteristics

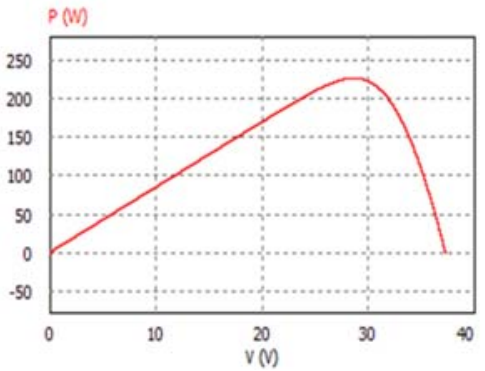

Figure 4. PV Power vs. voltage Vpv characteristics

The equation below represents the linearized model which is described by the tangent of the curve on the linearization point [5].

$$
i_{p v}=\left(-g V_{m p}+I_{m p}\right)+g v_{p v}
$$

The equivalent Thevenin model [8] is represented below with:

$$
R_{e q}=-1 / g \text { And } V_{e q}=V_{m p}-I_{m p} / g
$$

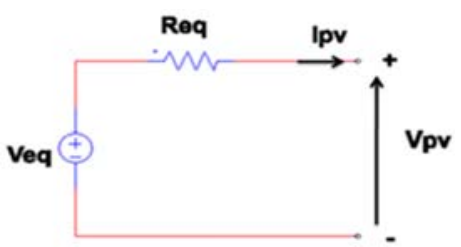

Figure 5. Thevenin model of PV

\subsection{Boost converter modelling}

An adaptation stage (Step up converter) is required to ensure the interface between GPV and load for a good optimization of the system's operation, it is essential to adapt the voltage and current of the GPV to the consumer's requirements, and it can also ensure the transfer of power between the GPV and the load, whether it is battery, DC load or inverter. Figure 6 shows the boost scheme corresponding to the GPV Thevenin model, The Step up converter operating in continuous conduction mode (CCM) [1, 2 and 7]. 


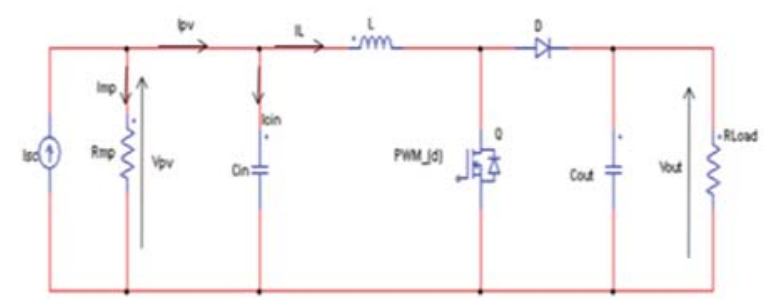

Figure 6. Thevenin model of PVG with boost adaptive stage

The electrical circuit of the lossless PV system is shown in Figure 6. The dynamic equations are designed to represent the system in the state space where the state variables are the inductive current and the voltage at the input capacitor, while the converter input is the duty cycle, the GPV is represented by the equivalent circuit model Thevenin, and $\mathrm{V}_{\mathrm{o}}$ is the Boost output voltage, $\mathrm{v}_{\mathrm{Cin}}$ represents the voltage of the input capacitor, $\mathrm{i}_{\mathrm{L}}$ is the inductive current and $\mathrm{d}$ is the duty cycle $[6,7$ and 8$]$.

Averaging state equations over a switching period period are given in the following set:

$$
\begin{aligned}
& v_{e q}-R_{e q} i_{p v}-v_{p v}=0 \\
& i_{p v}=i_{C i n}+i_{L} \\
& L \frac{d i_{L}}{d t}=v_{p v}-(1-d) v_{o} \\
& C_{o} \frac{d v_{c o}}{d t}=(1-d) i_{L}-\frac{v_{o}}{R_{o}}
\end{aligned}
$$

Control to input voltage transfer function:

$$
\frac{v_{p v}(s)}{d}=\frac{-R_{e q} v_{o}}{R_{e q}+L s+C_{i n} R_{e q} L s^{2}}
$$

Control to input voltage vs self current transfer function

$$
\frac{v_{p v}}{i_{L}}=-\frac{R_{e q}}{1+R_{e q} C_{i n} S}
$$

\section{MPPT DESIGN}

\subsection{Incremental conductance design}

The incremental conductance (IC) algorithm used to achieve maximum power point tracking (MPPT) uses the concept that the power derivative with respect to voltage will be zero at MPP and positive for voltages below MPP as well as negative for voltages above MPP, which is achieved with obvious ease when viewing the energy voltage curve $[9,10]$, Power-voltage curve as show in Figure 7.

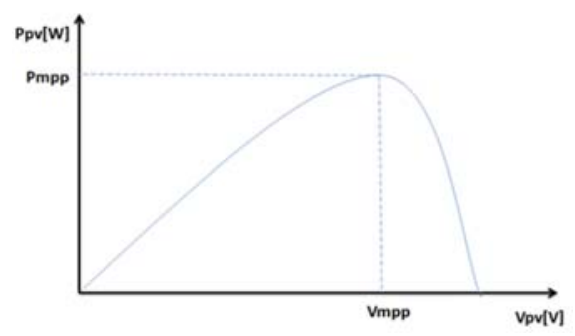

Figure 7. Power-voltage curve 
The power derivative with respect to the voltage can be expressed as (10) since $\mathrm{P}=\mathrm{IV}$ and new conditions on the variation of conductance are given (11).

$$
\begin{aligned}
& \frac{d P_{P V}}{d V_{P V}}=\frac{d\left(I_{P V} \cdot V_{P V}\right)}{d V_{P V}}=I_{P V}+V_{P V} \cdot \frac{d I_{P V}}{d V_{P V}} \cong I_{P V}+V_{P V} \cdot \frac{\Delta I_{P V}}{\Delta V_{P V}} \\
& \left\{\begin{array}{lll}
\frac{\Delta I_{P V}}{\Delta V_{P V}}>\frac{-I_{P V}}{V_{P V}} & \text { left } \quad \text { of } \quad M P P \\
\frac{\Delta I_{P V}}{\Delta V_{P V}}=\frac{-I_{P V}}{V_{P V}} & \text { at } \quad M P P \\
\frac{\Delta I_{P V}}{\Delta V_{P V}}<\frac{-I_{P V}}{V_{P V}} & \text { right } \quad \text { of } \quad M P P
\end{array}\right.
\end{aligned}
$$

The slop $d P_{P V} / d V_{P V}$ indicates the modified conditions for the change in conductance. The control point is located at the left-hand side of the MPP if the slope is greater than zero, at the right-hand side of the MPP the slope if the slope is less than zero, and the slope is zero exactly at the MPP. Therefore, the PV voltage needs to be increased when the slope is positive and decreased when the slope is negative.

In the previous section, Incremental Conductance is applied to determine the voltage Vref which aims to deliver the maximum power available in the stable state $[11,12]$. It is also desirable that the system converge more quickly to the MPP when the irradiation is changed. The proposed architecture of the Model Reference Adaptive Control (MRAC) is designed to maintain a critical damping behaviour of the GPV voltage (Vpv) $[13,14]$. The Figure 8 shows the basic structure of MRAC controller.

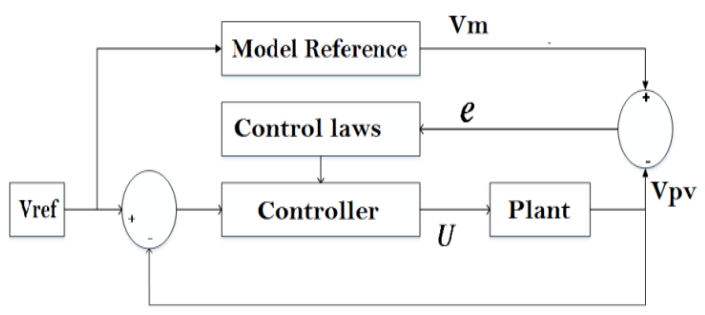

Figure 8. Basic structure of the adaptive control with the reference model

The transfer function of the GPV voltage with respect to the current iL is given below:

$$
\frac{v_{p v}(s)}{i_{L}}=\frac{-R_{e q}}{R_{e q} C_{i n} \cdot s+1}
$$

It is a transfer function of a first-order system, The design of MRAC is performed by selecting a first-order reference model to avoid exceeding the GPV voltage and have a very short stabilization time (settling time) $[15,16]$.

The reference model is of the following form

$$
G_{M}(s)=\frac{G_{r e f}}{V_{r e f}}=\frac{a}{s+a}
$$

Where $G_{\text {ref }}$ is the form of the desired GPV voltage, and $V_{\text {ref }}$ is the voltage calculated by the incremental conductance algorithm $[17,18]$. The error between the desired voltage $\mathrm{G}_{\mathrm{ref}}$ and the measured voltage $\mathrm{V}_{\mathrm{pv}}$ (or actual) is defined as follows:

$$
e=G_{r e f}-V_{P V}
$$

Expressing the equation of the model (12) in the time domain and simplification gives

$$
\frac{d V_{P V}}{d t}=-A V_{P V}+B I_{L r e f}
$$


with

$$
A=\frac{1}{R_{e q} C_{i n}}, B=\frac{-1}{C_{\text {in }}}
$$

The rewriting of 17 in the time domain gives

$$
\frac{d G_{r e f}}{d t}=-a G_{r e f}+a V_{r e f}
$$

From the (17), it can be deduced that a zero-error means that the rate of change for these should also be equal in this case. Thus assimilating (15) and (17) and simplifying we can reach:

$$
I_{\text {Lref }}=X V_{\text {ref }}-Y V_{P V}
$$

where $\mathrm{X}=\mathrm{a} / \mathrm{B}$, and $\mathrm{Y}=(\mathrm{a}-\mathrm{A}) / \mathrm{B}$

For the system to follow the behavior of the first-order reference model, the following conditions must be met:

$$
\dot{e}=\dot{G_{r e f}}-\dot{V_{P V}}=0
$$

Using (15) and (17), and replacing in (19) we obtain

$$
\dot{e}=-a e+(B Y+A-a) V_{P V}+(a-B X) V_{r e f}
$$

For the voltage $\mathrm{Vpv}$ to be stable and to follow the reference voltage, the error and the error derivative between them must tend towards zero; in oder hand, a Lyapunov candidate function is defined (21) to study the stability of the overall the system [13].

$$
\begin{aligned}
& V(x)=\frac{x_{1}^{2}+x_{2}^{2}}{2} \\
& \dot{V}(e, X, Y)=-a e^{2}+\frac{1}{\gamma}(-a+A+B Y)\left(\gamma e V_{p v}+\dot{Y}\right)+\frac{1}{\gamma}(a-B X)\left(\gamma e G_{r e f}-\dot{X}\right)
\end{aligned}
$$

According to the Lyapunov criteria, to guarantee the stability of the system, the time derivative of the candidate function Lyapunov should negative semi definite i.e $\mathrm{V}(\mathrm{x})<0$. This equality is true for the (22) and which fulfils the following conditions.

$$
\begin{aligned}
& \dot{X}=\gamma e G_{r e f} \\
& \dot{Y}=-\gamma e V_{P V} \\
& X=\int \gamma e G_{r e f}+X_{0} \\
& Y=\int \gamma e V_{p v}+Y_{0} \\
& \dot{V}=-a e^{2}
\end{aligned}
$$

The (23) to (27) represent the law of adaptation, with $\mathrm{X}$ and $\mathrm{Y}$ being the adaptive gains and a is the positive constant that must be adjusted.

The above equations have been implemented in the PSIM for PV Systems to incorporate Model Reference Adaptive Controller as shown Figure 9.

The parameter $\boldsymbol{a}$ of the reference model defines the speed of theclosed-loop response. If we want to decrease the closed-loop response we have to increase the parameter $\boldsymbol{a}$ on the other hand if we want to increase the closed-loop we will have to reduce $\boldsymbol{a}$.

From the equations above that present the adaptation law, the only control parameter is the positive gain $\gamma$. For the effective control of the variation in the amplitude of the reference signal, the control parameter $\gamma$ plays an important role. its value is maintained high if the variation of the reference signal is large and low if the variation of the reference signal is small. In our case $\gamma=0.003$ and. $a=7000$ are chosen.

Int J Pow Elec \& Dri Syst Vol. 11, No. 1, Mar 2020 : $251-262$ 


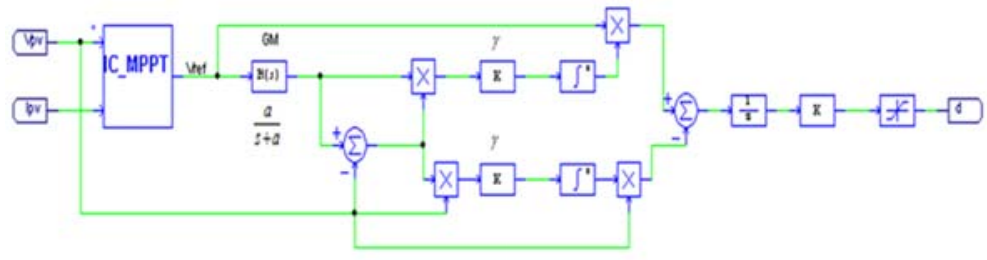

Figure 9. MRAC control law

\subsection{Super Twisting Sliding Control}

Super-twisting algorithm (STA) is a non-linear control technique and is one of the most powerful continuous 2-order SMCs which ensures all fundamental properties of its traditional 1-order with chattering reduction capability $[19,20]$. The main advantages of the STA are the robustness against variation of the system, and the ability to track the reference with high accuracy. It was developed in first time by Professor Levant for systems with a relative degree equal to 1 [21, 22]. This algorithm requires only the knowledge of the sliding variable and does not take into account its time derivative. In this work, the STA has been applied to drive the step-up converter with the purpose of keeping the GPV operating at the maximum power point.

The control law, as shown in Figure 10, is generated from a sliding surface treatment $\mathrm{s}(\mathrm{x})$. The control signal $\mathrm{u}(\mathrm{t})$ regulates the GPV voltage to operate at Vmp voltage via switch $\mathrm{S}$, it can be written as

$$
\begin{aligned}
& u(t)=\lambda \operatorname{Sign}(S)+u_{1}(t) \\
& u=\left\{\begin{array}{c}
-K u \text { if }|u|>1 \\
-W \operatorname{sign}(s) \text { if }|u|<1
\end{array}\right.
\end{aligned}
$$

where the sliding surface is defined as:

$$
S=e+K \int e
$$

And

$$
e=V_{\text {ref }}-V_{p v}
$$

The above algorithm does not require the evaluation of the sign of S. A second order sliding mode, exponentially stable, appears if the control law with $r=1$ is used. The parmeter $\rho=0.5$ guarantee that the fulfilment of the second order sliding is achieved [23, 24].

The control law is in this case given by:

$$
u=\left\{\begin{array}{c}
\dot{u}_{1}=-K_{1} \operatorname{Sign}(S) \text { si }|u|>u_{0} \\
u_{2}=-K_{2}|S|^{0.5} \operatorname{sign}(S) \text { si }|u| \leq u_{0}
\end{array}\right.
$$

The simplicity of the control law structure is quite obvious with only four parameters to be determined. Convergence conditions for these parameters are [25]:

$$
u_{0}>\frac{C_{0}}{K_{m}} ; \quad k, W>0
$$

The switching control ensures the convergence of the entire system by keeping it moving on the sliding surface while ensuring robustness against external uncertainties and disturbance .Therfore $\lambda / u_{0}$ should be a high value.

The overall control law is implemented in PSIM tools as follow: 


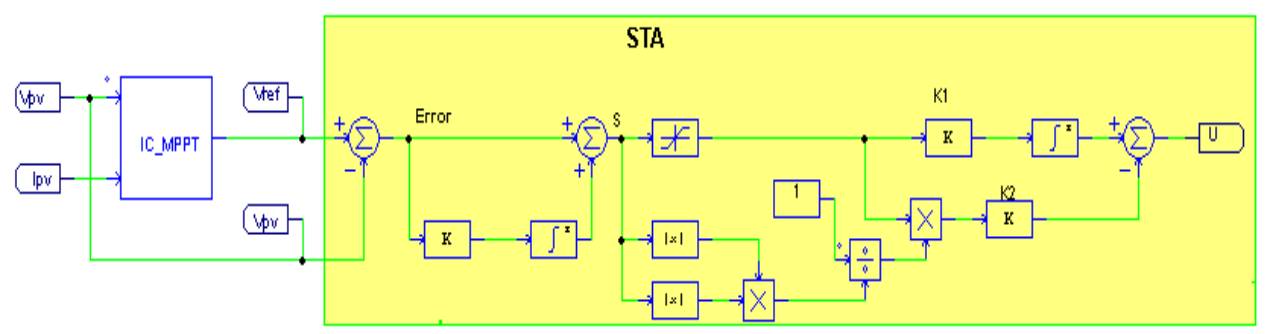

Figure 10. The synoptic diagram of the super-twisting algorithm.

\section{SIMULTION RESULTS}

In order to have a proper characterization of the algorithms proposed in this paper, simulations were performed using the PSIM software. Its takes into consideration the various operating conditions, steady state and transient state due to the variations in solar radiation (from $650 \mathrm{~W} / \mathrm{m} 2$ to $1000 \mathrm{~W} / \mathrm{m} 2$, temperature $\left(25^{\circ} \mathrm{C}\right.$ to $75^{\circ} \mathrm{C}$ ) and charge variation.

The figure 11(a), 11(b) shows the simulation model of MRAC and SMC controller with PSIM. The figures 12, 13 indicate the simulation resultof the GPV output current, voltage and GPV power for different operation conditions.

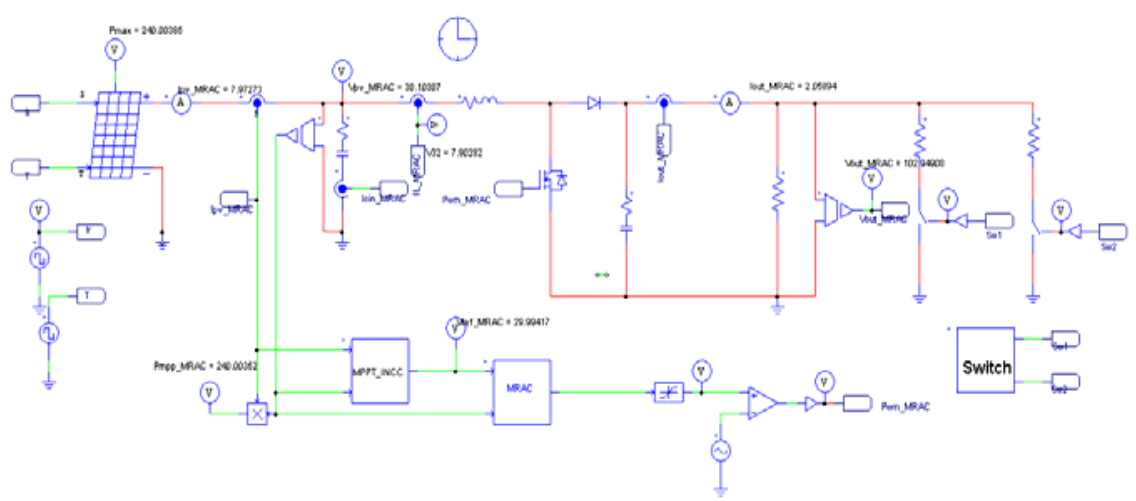

(a)

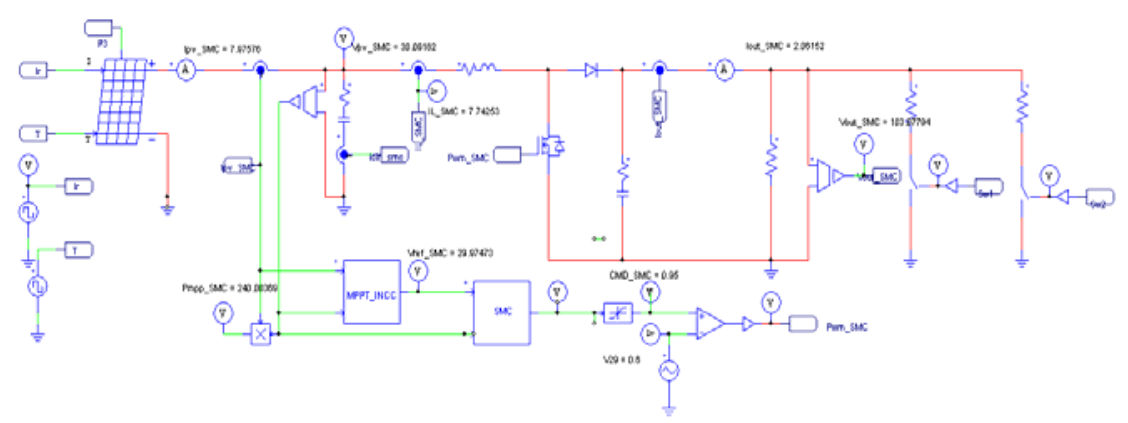

(b)

Figure 11. Simulation model (a) MRAC, (b) SMC

\subsection{In case of irradiation change:}

The two proposed method is efficient and extracts the maximum power, but the MRAC control combined with INC has a highest rise time compared with SMC as it can be seen in Figure 12(a). We can see also, in steady state, that MRAC have the higher oscillation around the maximum point, In addition; the GPV voltage is regulated to follow the reference voltage Vmp of the photovoltaic panel generated by INCC 
algorithm with less oscillation around it, in this case, the MRAC control affects the voltage of the GPV, which leads to oscillations around Vmpp (160mV vs $42 \mathrm{mV}$ for SMC). Also, the results also confirm that the optimal current is directly depend upon the solar illumination and is significantly affected by the sudden change Figure (c), instead of the optimal voltage, which is slightly affected Figure 12(b).

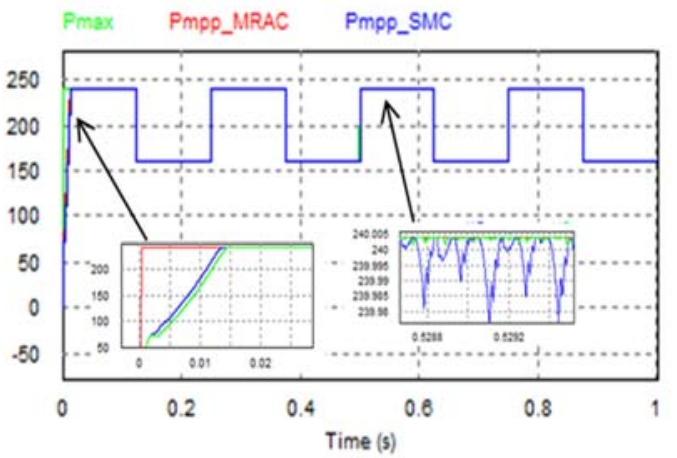

(a)

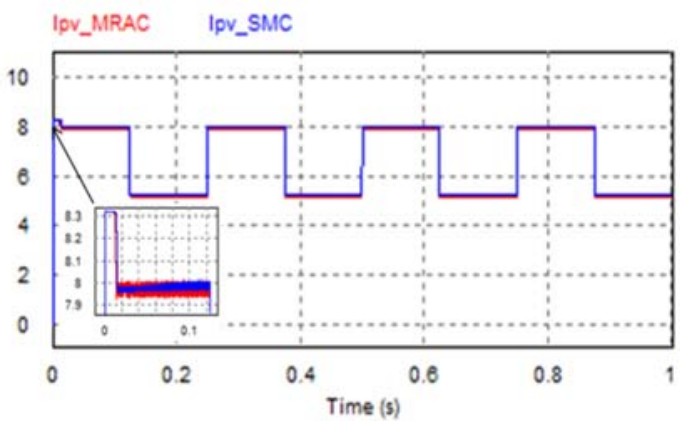

(c)

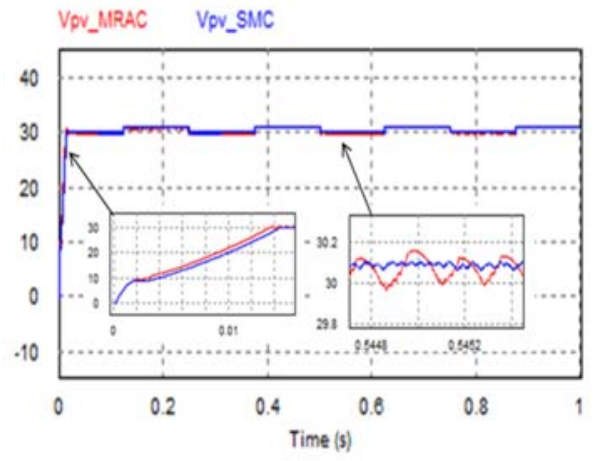

(b)

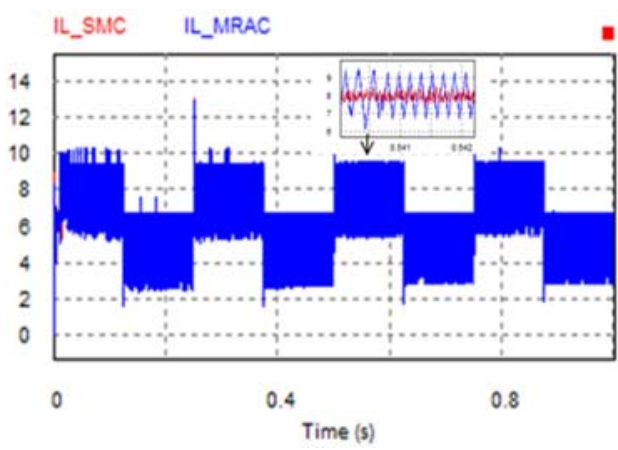

(d)

Figure 12. Simulation resultswith irradiation variation: a) Output power of GPV;

b) output voltage of GPV; c) Current of GPV, d) Load output current.

\subsection{In case of load variation and temperature}

Figure 13 shows that both approaches have an effective performance to extract maximum power despite the change in temperature and load but still the SMC method has a faster response and a greater capacity compared to MRAC to follow the reference voltage Vmp of the photovoltaic panel. So, the MRAC algorithm is an efficient algorithm but has oscillations around the optimal value as shown in Figure 13 (b). This algorithm has a big inconvenience which is its poor behaviour after an abrupt change in temperature and loadings of loads. In addition, the SMC is characterized by its robustness, its efficiency and its stability.

Nevertheless, the set-up of this kind of algorithm is more complex than traditional algorithms. We therefore evaluated and compared these algorithms of each method to show the effectiveness of the method compared to the others. 


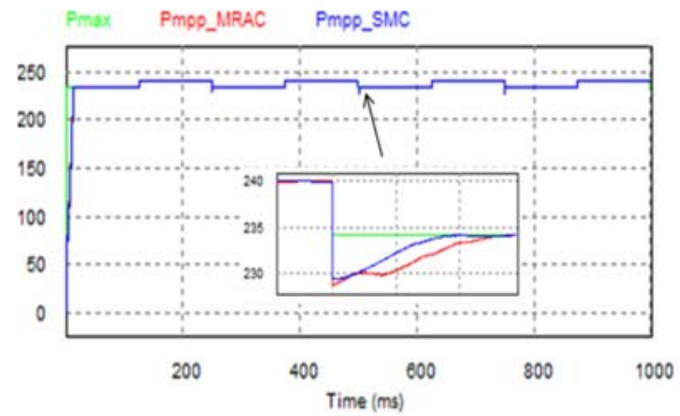

(a)

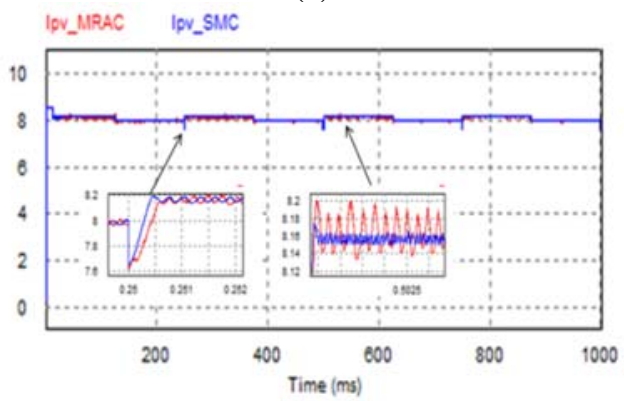

(c)

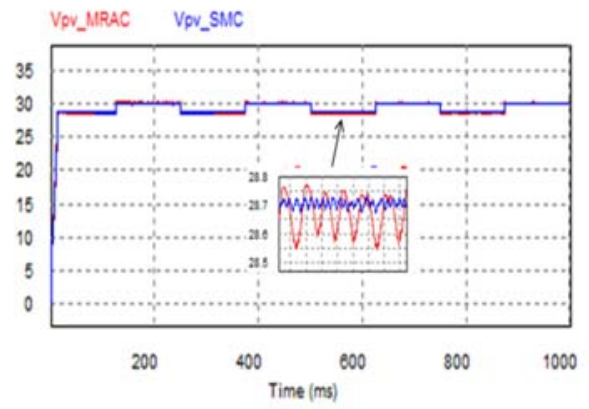

(b)

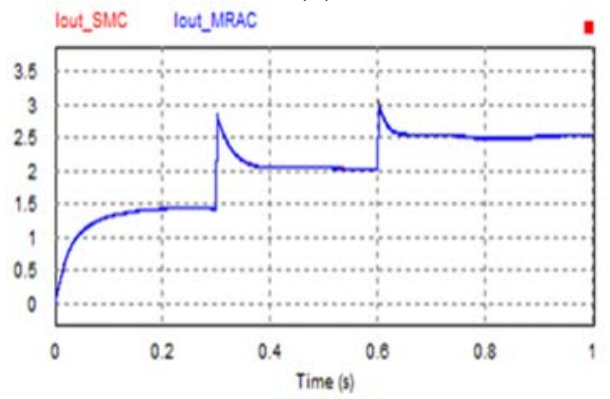

(d)

Figure 13. Differents simulation results for load variation and temperature: (a) Output power of GPV; (b) output voltage of GPV; (c) Current of GPV, (d) Load output current

\section{EXPERIMENTAL TEST AND DISCUSSION}

The Boost converter is used to transfer power from the input of the converter to this output, and to increase the low PV output voltage to a high voltage DC bus the Boost converter is used as an adaptation stage. The two signals used for the implementation of the MPPT algorithm and the voltage regulation loop are detected by an ACS711 current sensor (-12.5A to $+12.5 \mathrm{~A}$ ) for $\mathrm{I}_{\mathrm{PV}}$, and by a resistive divider for $\mathrm{V}_{\mathrm{PV}}$ and are interfaced by an STM32F407 Discovery board via the ADC channels for controlling the DC-DC converter. The STM32 controls the hardware part using a PWM output for switching the MOSFET transistor (SCH2080KE).

The description of the software and hardware block for running the main loop is shown in the following Figure 14.

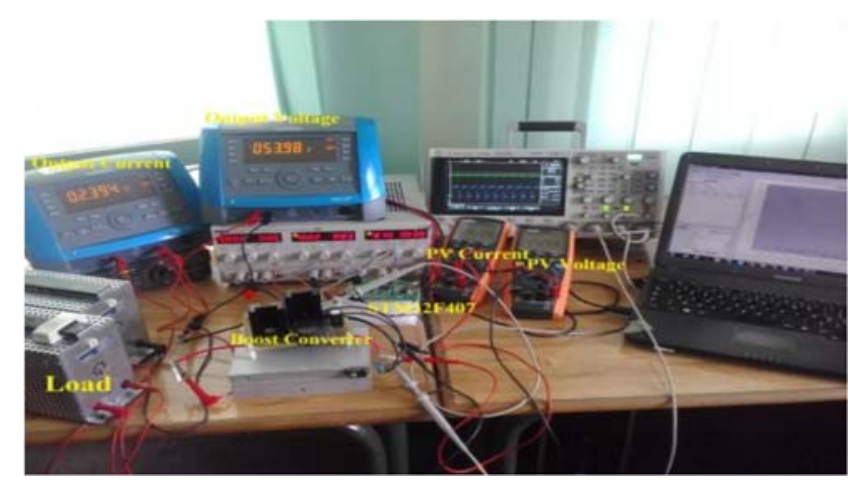

Figure 14. Experimental system bloc

The data acquisition of PV voltage and current are logging throughout the tools STMStudio, the experimental results was plotted in the Figure 15, 16, 17. 


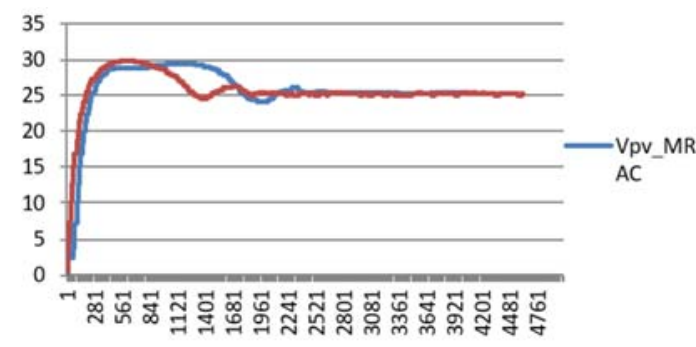

Figure 15. GPV voltage of MRAC and SMC

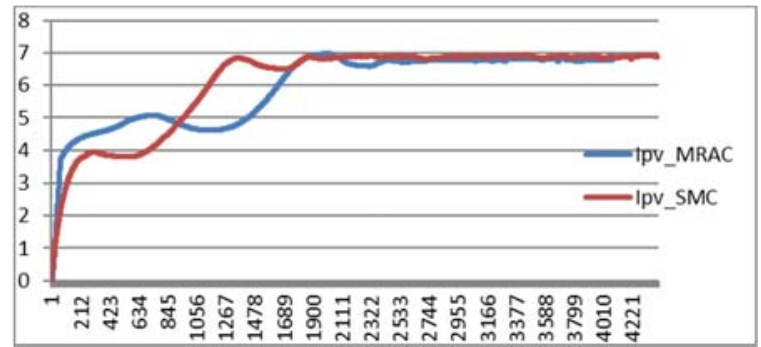

Figure 16. GPV voltage of MRAC and SMC

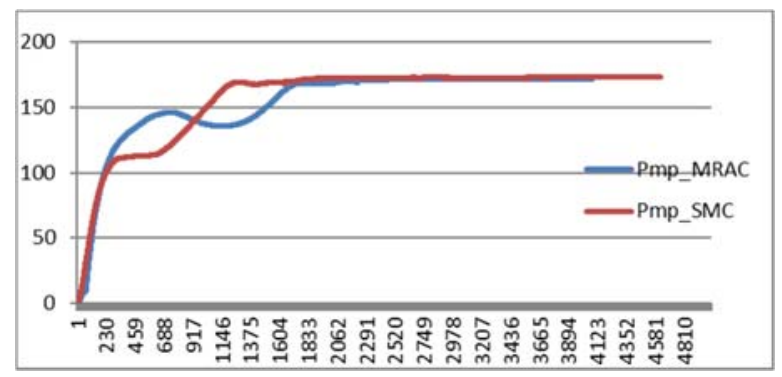

Figure 17. Maximum power from GPV (MPP) of MRAC and SMC

The input PV voltage of the MRAC and SMC control is plotted in Figure 15 and shows that the SMC controller was able to maintain the PV voltage constant at $24.5 \mathrm{~V}$ and a current of $7.63 \mathrm{~A}$, while for the MRAC controller, this voltage varies and exhibits an oscillation. The response of the input PV current for both methods is presented in Figure 16, and illustrates that the Ipv-smc converges rapidly towards the Ipv compared to the Ipv-mrac.

The PV power response for both controllers is shown in Figure 14. These results indicate that the SMC and MRAC controllers have the capabilities to converge at or near the maximum power point. The dynamic results confirm the effectiveness of the SMC method to converge quickly, without steady state oscillations, and recovering the power as much as possible from GPV. The IC+ MRAC method has a slow start-up response with PV voltage ripple.

\section{CONCLUSION}

In this paper, the main elements of the PV system have been described. Afterwards, we discussed the principle of two new and most efficient MPPT controllers. We finished the study by simulation with PSIM tool and experimental test of the two algorithms under the different conditions of irradiation, temperature and charge. The simulation results show that the SMC algorithm performs better than the MRAC. On the other hand, the SMC method is more efficient and has a higher efficiency than the MRAC control method.

\section{ACKNOWLEDGEMENTS}

The authors would like to thank IRESEN (Moroccan Research Institute for Solar and New Energy) for the financial support of the research project on $6 \mathrm{kVA}$ inverters.

\section{REFERENCES}

[1] Tariba, N., Haddou, A., El Omari, Hafsa, et al., "Design and implementation an adaptive control for MPPT systems using Model Reference Adaptive Controller," in 2016 International Renewable and Sustainable Energy Conference (IRSEC), IEEE, pp. 165-172, 2016.

[2] Tariba, N., Bouknadel, A., Haddou, A., et al., "Comparative study of adaptive controller using MIT rules and Lyapunov method for MPPT standalone PV systems," in AIP Conference Proceedings. AIP Publishing, pp. 040008, 2017. 
[3] Safari, Azadeh, and Saad Mekhilef. "Simulation and hardware implementation of incremental conductance MPPT with direct control method using cuk converter." IEEE transactions on industrial electronics, Vol 58, No. 4, pp. 1154-1161, 2010.

[4] A. Pradeep Kumar Yadav, S. Thirumaliah, G. Haritha, "Comparison of MPPT Algorithms for DC-DC Converters Based PV Systems," IJAREEIE, Vol. 1, NO. 1, 2012.

[5] Balakrishna S, Thansoe, Nabil A, Rajamohan G, Kenneth A.S., Ling C. J., "The Study and Evaluation of Maximum Power Point Tracking Systems," International Conference on Energy and Environment, 2006.

[6] Liu Xuejun, "An improved perturbation and observation maximum power point tracking algorithm for PV panelsl," thesis presented for the Degree of Master of Applied Science at Concordia University Montreal, Canada, 2004.

[7] Schott: Schott Perform ${ }^{\mathrm{TM}}$ Poly series Available at http://ozzyfortunegroup.com.au/wp-content/ uploads/2015/01/SH-DATA-QA-001-SCHOTT-PERFORM-POLY-235-250-EN-0812-V0.pdf.

[8] Moshiur Rahman Sourov, Ummee Tania Ahmed, Mirza Golam Rabbani, "A High-Performance Maximum Power Point Tracker for Photovoltaic Power System Using DC-DC Boost Converter," IOSR Journal of Engineering, Vol. 2, No. 12, pp 12-20, 2012.

[9] Villalva, M. G., de Siqueira, T. G., et Ruppert, E., "Voltage regulation of photovoltaic arrays: small-signal analysis and control design," IET Power Electronics, Vol. 3, No. 6, p. 869-880, 2010.

[10] T. Esram and P. L. Chapman, "Comparison of photovoltaic array maximum power point tracking techniques," IEEE Trans. Energy Convers., Vol. 22, No. 2, pp. 439-449, 2007.

[11] H. S. Bae, S. J. Lee, K. S. Choi, B. H. Cho, S. S. Jang, "Current control design for a grid connected photovoltaic/fuel cell DC-AC inverter," in Proc. 24th IEEE APEC, pp. 1945- 1950, 2009.

[12] Salem, Farhan A. et Rashed, Albaradi A., "PID Controllers and Algorithms: Selection and Design Techniques Applied in Mechatronics Systems Design-Part II," International Journal of Engineering Sciences, Vol. 2, No. 5, pp. 191-203, 2013.

[13] Ortiz-Valencia, Paula Andrea, Trejos-Grisales, Luz Adriana, et Ramos-Paja, Carlos Andrés, "Maximum power point tracking in PV systems based on adaptive control and sliding mode control," RevistaFacultad de Ingeniería Universidad de Antioquia, No 75, pp. 69-76, 2015.

[14] Cao, Chengyu et Hovakimyan, Naira, "Design and analysis of a novel 11 adaptive controller, part ii: Guaranteed transient performance," in 2006 American Control Conference, IEEE, pp. 3403-3408, 2006.

[15] Aguila-Camacho, Norelys, Duarte-Mermoud, Manuel A., et Gallegos, Javier A., "Lyapunov functions for fractional order systems," Communications in Nonlinear Science and Numerical Simulation, Vol. 19, No 9, pp.. 2951-2957, 2014.

[16] Prakash, R. et Anita, R., "Robust model reference adaptive PI control," Journal of Theoretical and Applied Information Technology, Vol. 14, No. 1, pp. 51-59, 2010.

[17] Cao, Chengyu et Hovakimyan, Naira, "Design and analysis of a novel 11 adaptive controller, part ii: Guaranteed transient performance, in 2006 American Control Conference,IEEE, pp. 3403-3408, 2006.

[18] Yau, Her-Terng, "Design of adaptive sliding mode controller for chaos synchronization with uncertainties. Chaos, Solitons \& Fractals, Vol. 22, No 2, pp. 341-347, 2004.

[19] Tan, Siew-Chong, LAI, Yuk-Ming, et TSE, Chi K, "A unified approach to the design of PWM-based sliding-mode voltage controllers for basic DC-DC converters in continuous conduction mode," IEEE Transactions on Circuits and Systems I: Regular Papers, Vol. 53, No. 8, p. 1816-1827, 2006.

[20] Edwards, Christopher, Akoachere, Ashu, et Spurgeon, Sarah K., "Sliding-mode output feedback controller design using linear matrix inequalities," IEEE Transactions on Automatic Control, Vol. 46, No 1, pp. 115-119, 2001.

[21] Furuta, Katsuhisa, "Sliding mode control of a discrete system," Systems \& Control Letters, Vol. 14, No. 2, pp. 145-152, 1990.

[22] Utkin, Vadim, Guldner, Jürgen, et SHI, Jingxin, "Sliding mode control in electro-mechanical systems," CRC press, 2009.

[23] Perruquetti, Wilfrid et Barbot, Jean Pierre (ed.), "Sliding mode control in engineering. M. Dekker, 2002.

[24] Mori, Cláudia Narumi Takayama et Romão, Estaner Claro, "Numerical Simulation by Finite Difference Method of 2D Convection-Diffusion in Cylindrical Coordinates," Applied Mathematical Sciences, Vol. 9, no. 123, pp. 6157-6165, 2015.

[25] Chrifi-Alaoui, Larbi. "Second Order Sliding Mode Control of DC-DC Converter used in the Photovoltaic System According an Adaptive MPPT." International Journal of Renewable Energy Research (IJRER), Vol. 6, No. 2, pp. 375-383, 2016.

Int J Pow Elec \& Dri Syst Vol. 11, No. 1, Mar 2020 : $251-262$ 